\title{
Ligand substitution reactions of a phenolic quinolyl hydrazone; oxidovanadium (IV) complexes
}

\author{
Hussein S Seleem ${ }^{*}$ and Marwa A Mousa
}

\begin{abstract}
Background: Quinoline ring has therapeutic and biological activities. Quinolyl hydrazones constitute a class of excellent chelating agents. Recently, the physiological and biological activities of quinolyl hydrazones arise from their tendency to form metal chelates with transition metal ions. In this context, we have aimed to study the competency effect of a phenolic quinolyl hydrazone ( $\mathrm{H}_{2} \mathrm{~L}$; primary ligand) with some auxiliary ligands (Tmen, Phen or Oxine; secondary ligands) towards oxidovanadium (IV) ions.

Results: Mono- and binuclear oxidovanadium (IV) - complexes were obtained from the reaction of a phenolic quinolyl hydrazone with oxidovanadium (IV)- ion in absence and presence of $\mathrm{N}, \mathrm{N}, \mathrm{N}^{\prime}, \mathrm{N}^{\prime}$ - tetramethylethylenediamine (Tmen), 1,10-phenanthroline (Phen) or 8-hydroxyquinoline (Oxine). The phenolic quinolyl hydrazone ligand behaves as monobasic bidentate (NO- donor with O- bridging). All the obtained complexes have the preferable octahedral geometry except the oxinato complex (2) which has a square pyramid geometry with no axial interaction; the only homoleptic complex in this study.

Conclusion: The ligand exchange (substitution/replacement) reactions reflect the strong competency power of the auxiliary aromatic ligands (Phen/Oxine) compared to the phenolic quinolyl hydrazone $\left(\mathrm{H}_{2} \mathrm{~L}\right)$ towards

oxidovanadium (IV) ion; (complexes $\mathbf{2}$ and $\mathbf{3}$ ). By contrast, in case of the more flexible aliphatic competitor (Tmen), an adduct was obtained (4). The obtained complexes reflect the strength of the ligand field towards the oxidovanadium (IV)- ion; Oxine or Phen >> phenolic hydrazone $\left(\mathrm{H}_{2} \mathrm{~L}\right)>$ Tmen.
\end{abstract}

\section{Background}

The heterocyclic hydrazones constitute an important class of biologically active drug molecules which have attracted attention of medicinal chemists due to their wide ranging pharmacological properties including iron scavenging and anti- tubercular activities [1-4]. Literature survey revealed that quinolyl hydrazones have anticancer and anti- inflammatory activities [1]. Quinolyl hydrazones are known to function as chelating agents and have versatile modes of bonding [5-7]. Recently, the physiological and biological activities of quinolyl hydrazones arise from their tendency to form metal chelates with transition metal ions $[3,4]$. On the other hand, vanadium is a versatile bio-essential element capable of existing in a wide range of oxidation

\footnotetext{
* Correspondence: hsseleem@yahoo.com

Department of Chemistry, Faculty of Education, Ain Shams University, Roxy, Cairo, Egypt
}

states spanning between 3 - and $5+$, that advances the usefulness of this element in the biological milieu [8]. Current focus in the coordination chemistry of vanadium has been the subject of extensive research, stimulated by the potential pharmacological effects such as action against diabetes [8-11] and cancer [12,13], the stimulation of phosphomutases and isomerases as well as the ability of vanadium in the inhibition of sodium potassium ATPase enzymes [14,15] provide great impetus in vanadate-phosphate analogy [11]. This work is aimed to study the competency of a phenolic quinolyl hydrazone [5]; 4-[(2-(4,8-dimethylquinolin-2-yl) hydrazono)methyl] benzene-1,3-diol $\left(\mathrm{H}_{2} \mathrm{~L}\right.$; primary ligand) with some auxiliary ligands (Tmen, Phen or Oxine; secondary ligands) towards oxido-vanadium (IV)- ion (Scheme 1). 


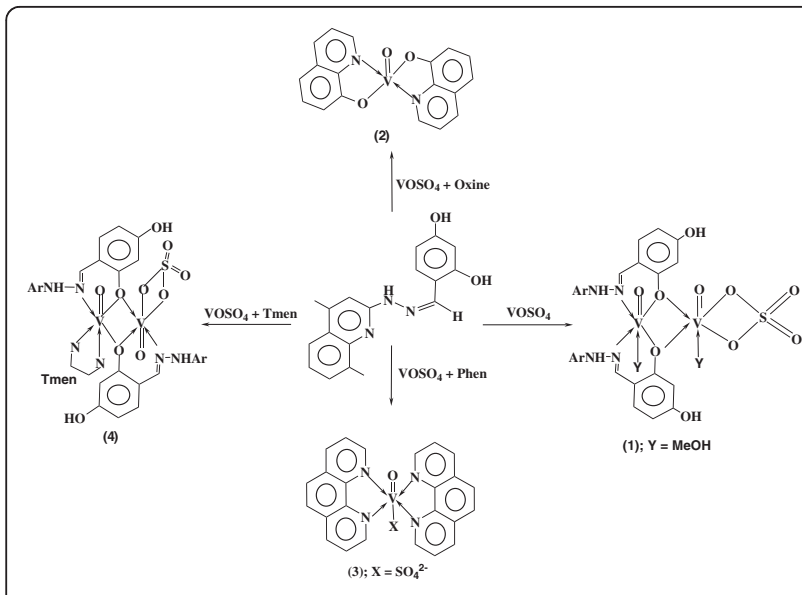

Scheme 1 Ligand substitution reactions.

\section{Results and discussion}

Effect of solvent on the spectra of the hydrazone

In this study, the electronic absorption spectra of the hydrazone $\left(2 \times 10^{-5} \mathrm{M}\right)$ were recorded in solvents of various polarities (Table 1 and Figure 1). The hydrazone displays mainly three bands, the shortest UV- bands $\left(\lambda_{1}=\right.$ 247-266 and $\left.\lambda_{2}=308-369 \mathrm{~nm}\right)$ are best ascribed to $\pi-\pi^{*}$ transitions of the aromatic system and they are solvent sensitive bands whereas, the longest UV- band $\left(\lambda_{3} \approx 370\right.$ $\mathrm{nm})$ is a strong broad band reflecting its charge transfer (CT) nature [6,7]. Most bands suffered a red shift on increasing the solvent polarity. Also, the less intense $n-\pi^{*}$ transitions are hidden under the more intense CT bands, especially in polar solvents. Correlation of the band shift $(\Delta \tilde{\nu})$ with the solvent parameters $[6,16] v i z .1 / \mathrm{D}$; (D is the dielectric constant), Kosower's (Z), Dimroth-Reichardt's $\left(E_{\mathrm{T}}\right)$, Kamlet- Taft's $\left(\alpha, \beta, \pi^{*}\right)$ or Gutmann's donoracceptor numbers (DN, AN) is not satisfactory as indicated by its non linearity. This reflects that $\Delta \tilde{\nu}$ is affected by more than one parameter e.g. polarity, donor- acceptor and acid- base properties of the solvents as well as solute- solvent interactions and $\mathrm{H}$ - bonding $[6,16]$.

\section{Competition study (ligand substitution reactions)}

The reaction of the phenolic hydrazone $\left(\mathrm{H}_{2} \mathrm{~L}\right)$ with $\mathrm{VOSO}_{4} \cdot \mathrm{H}_{2} \mathrm{O}$ afforded a binuclear complex (1). However, in an attempt to study the role of the auxiliary ligands on the formed complexes, the phenolic hydrazone $\left(\mathrm{H}_{2} \mathrm{~L}\right)$ was allowed to react with $\mathrm{VOSO}_{4} \cdot \mathrm{H}_{2} \mathrm{O}$ in presence of $\mathrm{N}$, N,N',N'-tetramethylethylenediamine (Tmen), 1,10-phenanthroline (Phen) or 8-hydroxyquinoline (Oxine) (Scheme 1). On refluxing $\mathrm{VOSO}_{4} \cdot \mathrm{H}_{2} \mathrm{O}$ with $\mathrm{H}_{2} \mathrm{~L}$ in presence of Oxine or Phen, a ligand substitution reaction takes place $[17,18]$ where an oxinato $(2)$ or a Phen $(3)$ complex was obtained in a moderate yield; Table 2 . In contrast, upon the reaction of $\mathrm{VOSO}_{4} \cdot \mathrm{H}_{2} \mathrm{O}$ with $\mathrm{H}_{2} \mathrm{~L}$ in presence of the more flexible aliphatic amine (Tmen), a mixed ligand complex (4) was obtained in good yield; Table 2. In these reactions, the aliphatic and the aromatic bases (Tmen and Phen) behave as neutral NNdonors [19] whereas the Oxine behaves as a monobasic NO-donor [2]. The obtained complexes reflect the strength of the ligand field towards the oxidovanadium (IV)- ion; Oxine or Phen >> phenolic hydrazone $\left(\mathrm{H}_{2} \mathrm{~L}\right)$, i.e. replacement of $\mathrm{H}_{2} \mathrm{~L}$ by Oxine or Phen. However, such replacement or substitution (ligand exchange) reactions indicate that the competitor ligands (Oxine/Phen) are strong ligands as compared to the phenolic hydrazone $\left(\mathrm{H}_{2} \mathrm{~L}\right)$. This may be due to the strong nucleophilicity of Oxine or Phen than that of phenolic hydrazone $\left(\mathrm{H}_{2} \mathrm{~L}\right)$ as well as the bulkiness and steric crowding of the latter. Structural elucidation of the isolated complexes was achieved via elemental and thermal analyses, magnetic susceptibility and conductivity measurements as well as spectral studies viz. electronic, vibration, mass and ESR spectra.

\section{IR spectra}

Inspection of the IR data revealed the following: The broad bands in the region $3420-3400 \mathrm{~cm}^{-1}$ are due to $\mathrm{OH}$ stretches. For the binuclear complexes 1 and $\mathbf{4}$, the strong band at $1618 \mathrm{~cm}^{-1}\left(1603 \mathrm{~cm}^{-1}\right.$ in the free ligand) supports the coordination of the hydrazone linkage to the oxidovanadium ion. This can be explained on the basis of the diminished repulsion between the lone pairs of electrons of the two adjacent $\mathrm{N}$-atoms upon complexation and hence, $\pi$-electron delocalization [20]. For the Oxinato (2) and Phen (3)- complexes, the aromatic ring vibrations around 1620,1580 and $1500 \mathrm{~cm}^{-1}$ due to

Table 1 Electronic spectral data*of the hydrazone in various solvents.

\begin{tabular}{|c|c|c|c|c|c|c|c|c|c|c|c|}
\hline Solvent & DMSO & DMF & 2-Propanol & $\mathrm{MeOH}$ & EtOH & Acetone & Dioxane & THF & Ethyl ether & Benzene & Ethyl acetate \\
\hline$\lambda_{1}$ & 266 & 265 & 247 & -- & - & - & 258 & - & 253 & - & 261 \\
\hline$\varepsilon_{1}$ & 17927 & 17288 & 20629 & -1 & -— & - - & 17191 & - & 21080 & - - & 14888 \\
\hline$\lambda_{2}$ & 364 & 321 & 308 & 312 & 322 & 335 & 351 & 369 & 345 & 343 & 347 \\
\hline$\varepsilon_{2}$ & 19104 & 17688 & 18887 & 18304 & 18089 & 17391 & 22614 & 13575 & 19566 & 17421 & 18592 \\
\hline$\lambda_{3}$ & - & 372 & 372 & 370 & 369 & 367 & - & - & - & - & - \\
\hline$\varepsilon_{3}$ & - & 19040 & 19329 & 19580 & 19416 & 18148 & - & - & - & - & - \\
\hline
\end{tabular}

* $\lambda$ in $\mathrm{nm}$ and $\varepsilon$ in $(\mathrm{cm} \mathrm{mol} / \mathrm{L})^{-1}$. 

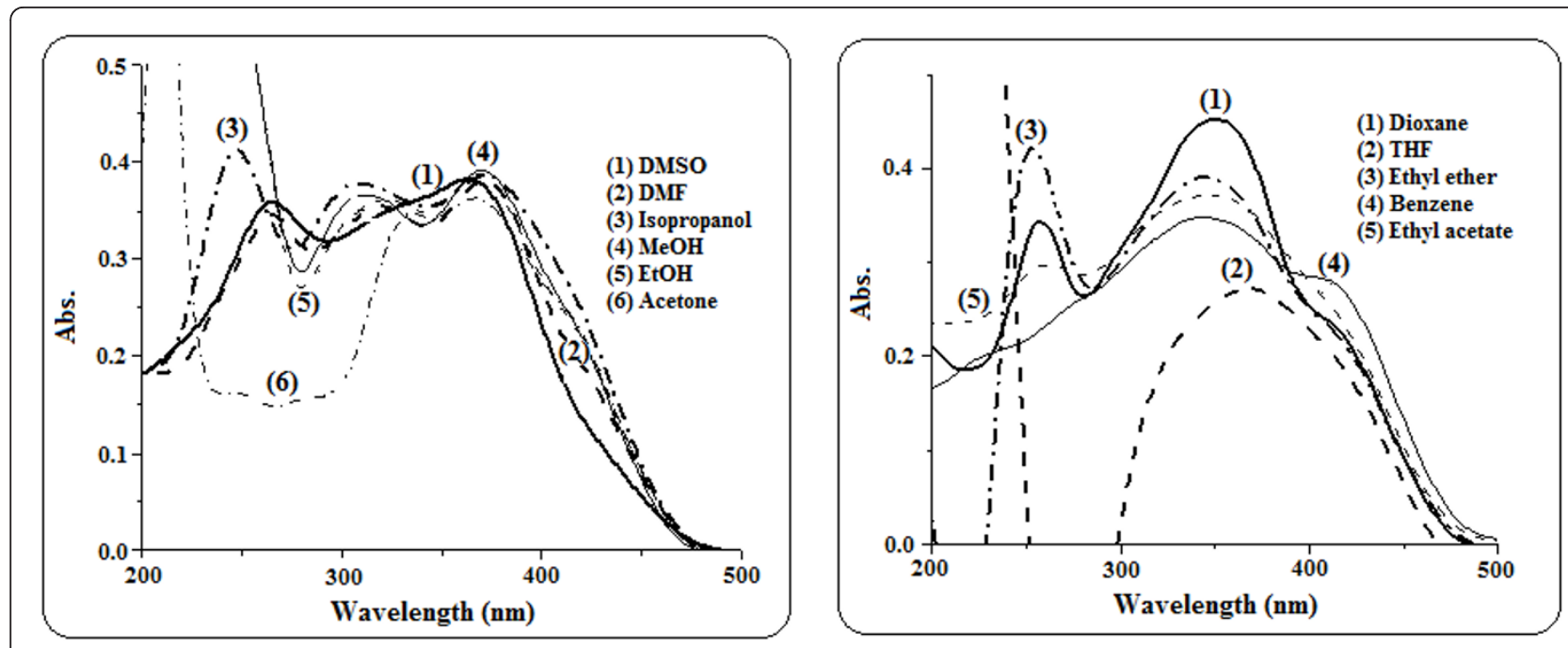

Figure 1 Electronic absorption spectra of $\mathrm{H}_{2} \mathrm{~L}$ in various solvents.

the quinoline and 1,10- phenanthroline rings are shifted to higher wave numbers for the former and to lower wave numbers for the latter, suggesting the participation of the heterocyclic $\mathrm{N}$ - atoms in the chelation [19]. Also, their intensities are greatly altered. The sulfato- complexes $(\mathbf{1}, \mathbf{3}, \mathbf{4})$ showed the $v(\mathrm{~S}-\mathrm{O})$ stretches as strong bands around $1100 \mathrm{~cm}^{-1}$ [21]. The characteristic $v(\mathrm{~V}=$ O) stretches [20,22] were observed at 984, 1010, 854 and $975 \mathrm{~cm}^{-1}$; respectively. The higher value at 1010 $\mathrm{cm}^{-1}$ is for the penta- coordinated oxinato- complex (2) which is most probably due to the strong $\mathrm{O} \rightarrow \mathrm{V} \rightarrow$ bonding [20], supporting the non axial interaction (Figure 2c). In contrast, the lower values for the hexa- coordinated complexes $(\mathbf{1}, \mathbf{3}, \mathbf{4})$ suggest an axial interaction which lying trans to $\mathrm{V}=\mathrm{O}$ (Figure 2a,b). In general, the $v(\mathrm{~V}=\mathrm{O})$ stretches are highly affected by the axial interactions trans to $\mathrm{V}=\mathrm{O}$ stretches [20]. However, this could be explained by using the well known BallhausenGray molecular orbital (M.O.) energy level diagram [23]; (Figure 2).

\section{Conductivity and magnetic measurements}

The molar conductance values of the current chelates in DMF $(1 \mathrm{mmol} / \mathrm{L})$ were measured at room temperature and the results are listed in Table 3 . The values reflect the non- electrolytic nature of all complexes. The oxidovanadium (IV) complexes (1-4); $\mathrm{d}^{1}$ - system exhibit $\mu_{\text {eff }}$ values in the range 1.27-1.90 B.M. (Table 3) indicating the presence of one unpaired electron. The subnormal $\mu_{\text {eff }}$ values indicate $\mathrm{VO}-\mathrm{VO}$ interactions in the solid state; supporting the binuclear nature of the complexes (1 and 4).

\section{Electronic spectra}

Solution electronic spectra of the complexes in DMF (Table 3) are more or less similar and show a series of bands within the range $267-341 \mathrm{~nm}$ due to intra-ligand transitions. Unfortunately, although the oxidovanadium (IV)- complexes (1-4) are the easiest of the $\mathrm{d}^{1}$ - systems to use experimentally, the interpretation of the spectra has been complicated by the deviation of the complexes from regular octahedral stereochemistry [24]. Three bands are normally observed around 485, 460 and 430 $\mathrm{nm}$ in case of the phenolic complexes (1) and (4). On a simple crystal field model, these bands would be interpreted as the transitions from the ${ }^{2} \mathrm{~B}_{2}$ - ground term to the ${ }^{2} \mathrm{E},{ }^{2} \mathrm{~B}_{1}$ and ${ }^{2} \mathrm{~A}_{1}$ - terms [24], respectively. However, such a treatment does not give a good quantitative fit to the spectra and the axial $\pi$-bonding must be taken into account. In case of the oxinato (2) and Phen (3)

Table 2 Physical and analytical data of the complexes.

\begin{tabular}{|c|c|c|c|c|c|c|c|}
\hline \multirow[t]{2}{*}{ No. } & \multirow[t]{2}{*}{ Reactants } & \multirow[t]{2}{*}{$\begin{array}{l}\text { Complex } \\
\text { (F.W.) }\end{array}$} & \multirow[t]{2}{*}{ Color } & \multirow[t]{2}{*}{$\%$ Yield } & \multicolumn{3}{|c|}{$\begin{array}{l}\text { Elemental Analysis; } \\
\% \text { Found/(Calc.) }\end{array}$} \\
\hline & & & & & C & $\mathrm{H}$ & $\mathbf{N}$ \\
\hline 1 & $\mathrm{H}_{2} \mathrm{~L}+\mathrm{VO} \mathrm{SO}_{4}$ & {$\left[(\mathrm{VO})_{2}(\mathrm{HL})_{2}(\mathrm{MeOH})_{2} \mathrm{SO}_{4}\right] \cdot 2 \mathrm{MeOH}(970.78)$} & Olive green & 36 & $49.44(49.49)$ & $7.92(7.98)$ & $8.70(8.66)$ \\
\hline 2 & $\mathrm{H}_{2} \mathrm{~L}+\mathrm{VO} \mathrm{SO}_{4}+$ Oxine & $\left.[(\mathrm{VO}) \text { (oxinate) })_{2}\right] 1 / 4 \mathrm{H}_{2} \mathrm{O}(359.74)$ & Olive green & 40 & $60.12(60.09)$ & $3.59(3.50)$ & $8.31(7.80)$ \\
\hline 3 & $\mathrm{H}_{2} \mathrm{~L}+\mathrm{VO} \mathrm{SO}_{4}+$ Phen & {$\left[(\mathrm{VO})(\mathrm{Phen})_{2}\left(\mathrm{SO}_{4}\right)\right] .21 / 2 \mathrm{H}_{2} \mathrm{O} .41 / 4 \mathrm{MeOH}(704.63)$} & Olive green & 61 & $47.97(48.15)$ & $5.45(5.44)$ & $7.95(7.95)$ \\
\hline 4 & $\mathrm{H}_{2} \mathrm{~L}+\mathrm{VO} \mathrm{SO}_{4}+$ Tmen & {$\left[(\mathrm{VO})_{2}(\mathrm{HL})_{2}(\mathrm{Tmen}) \mathrm{SO}_{4}\right] .6 \mathrm{H}_{2} \mathrm{O}(1066.92)$} & Coffee brown & 70 & $47.18(47.28)$ & $5.62(5.67)$ & $10.60(10.51)$ \\
\hline
\end{tabular}




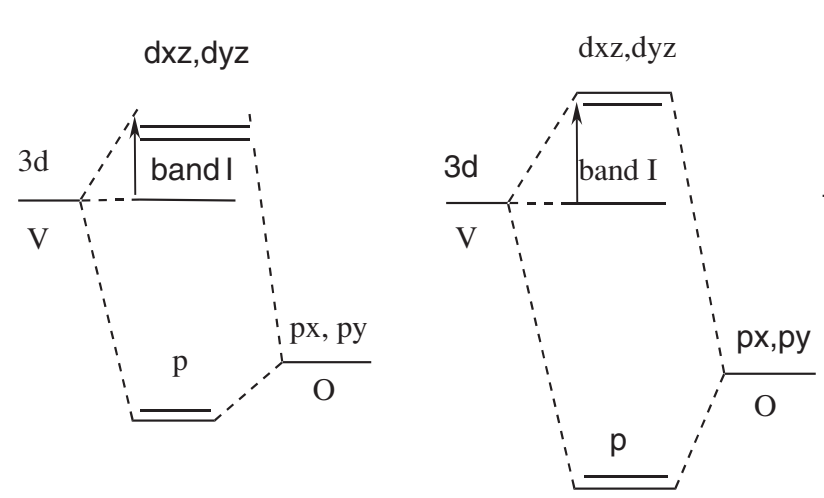

(a) strong field

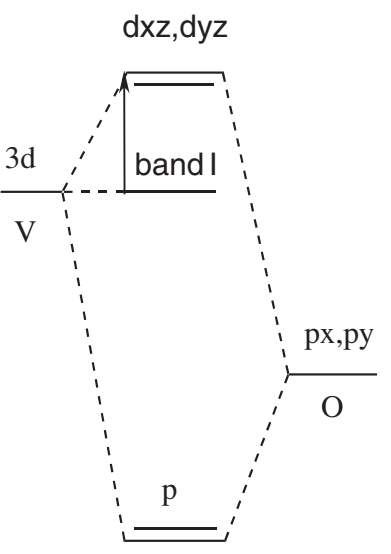

(c) no interaction

Figure 2 Ballhausen - Gray M.O. energy level diagram; (Band I as a function of the strength of the axial interaction; trans to $\mathrm{V}=0$ ).

complexes, only the transition ${ }^{2} \mathrm{~B}_{2} \rightarrow{ }^{2} \mathrm{~A}_{1}$ was observed at 412 and $341 \mathrm{~nm}$, respectively.

\section{ESR spectroscopy}

To obtain further information about the stereochemistry as well as the magnetic properties of the complexes, the ESR spectra of a powdered sample of complexes $\mathbf{1}$ and 4 were recorded at room temperature (Figure 3). The shape and the features of the obtained spectra are consistent with the $\mathrm{O}_{\mathrm{h}}$-geometry around the metal ion. The ESR spectrum of the adduct (4) displayed one strong signal with $g_{\text {eff }}=2.094$ and a shoulder at $g=2.44$. Also, a very weak signal at $\sim 1700$ Gauss due to the forbidden $\Delta \mathrm{M}_{\mathrm{s}}= \pm 2$ transition, characteristic of dimeric vanadyl (II) -complexes. This is consistent with the lower $\mu_{\text {eff }}=$ 1.27 B.M. (Table 3). In contrast, the ESR spectrum of the phenolic complex (1) displayed the high field component at $g_{\perp}=2.084$ and the low field component at $g_{11}$ $=2.208 ; g_{\text {eff }}=1 / 3\left(g_{11}+2 g_{\perp}\right)=2.125$. The positive contribution in the $g_{\text {eff }}$ value than that of the free electron $\left(g_{e}=2.0023\right)$ indicates an increase in the covalency of the bonding. In axial symmetry, the value of the exchange interaction parameter; $\mathrm{G}=\left(g_{11}-\mathrm{g}_{\mathrm{e}}\right) /\left(g_{\perp}-\mathrm{g}_{\mathrm{e}}\right)=$ 2.518 indicates a considerable $\mathrm{OV}--\mathrm{VO}$ interaction

Table 3 Magnetic, conductivity and electronic spectral data of the complexes.

\begin{tabular}{cccc}
\hline Complex & $\begin{array}{c}\text { Electronic Spectral } \\
\text { Bands (nm) }\end{array}$ & $\begin{array}{c}\boldsymbol{\mu}_{\text {eff }} \\
\text { B.M. }\end{array}$ & $\begin{array}{c}\text { Conductance } \\
\mathbf{O h m}^{-1} \mathbf{~ c m}^{\mathbf{2}} \mathbf{~ m o l}^{-1}\end{array}$ \\
\hline $\mathbf{1}$ & $282,341,435,460,483$ & 1.59 & 13.7 \\
$\mathbf{2}$ & 268,412 & 1.90 & 7.40 \\
$\mathbf{3}$ & 268,341 (sh.) & 1.83 & 29.3 \\
$\mathbf{4}$ & 267,336 (sh.), 430 (sh.), 456, & 1.27 & 12.5 \\
& 486 (sh.) & & \\
\hline
\end{tabular}

which is also consistent with the lower $\mu_{\text {eff }}=1.59$ B.M. (Table 3) as well as the absence of hyperfine coupling. The latter is attributed to either the simultaneous flipping of neighboring electron spins or the strong exchange interaction [25].

\section{Mass spectra}

The mass spectra of complexes 2 and 3 showed the molecular ion peaks at $m / z=356$ and 698 and the base peaks at 145 and 46, respectively, confirming their formulae weights (Table 2). The Oxinato- complex (2) showed the molecular ion peak at 356 which agree well with the formula weight of the non-hydrated complex $($ F.W. $=355.24) ;\left[(\mathrm{VO})(\text { Oxinate })_{2}\right]$. Furthermore, the base peak at 145 which is identical to the charged Oxine species- provides strong evidence for the structure of the Oxinato complex (Scheme 2).

\section{Thermal properties of the complexes}

TGA data of the complexes (1-4) showed good agreement with the results of elemental analyses. The decomposition occurs in two or three steps according to the nature of each complex. Attempts to generalize the thermal degradation patterns were unsuccessful indicating that there is no simple relation or general trend for explaining these thermal degradations. However, the decomposition ends with the formation of $(\mathrm{VO})_{2}$ for the phenolic binuclear complexes $\mathbf{1}$ and $\mathbf{4}$. The Phen complex (3) decomposes into two stages and undergoes a structural rearrangement upon thermal degradation [26-28]; (Scheme 3). This structural rearrangement was confirmed from the considerable decrease of the values of $\mathrm{A}, \mathrm{E}^{*}$ and $\Delta \mathrm{H}^{*}$ for the second stage than that for the first stage; Table 4. Also, the only adduct in this study; 

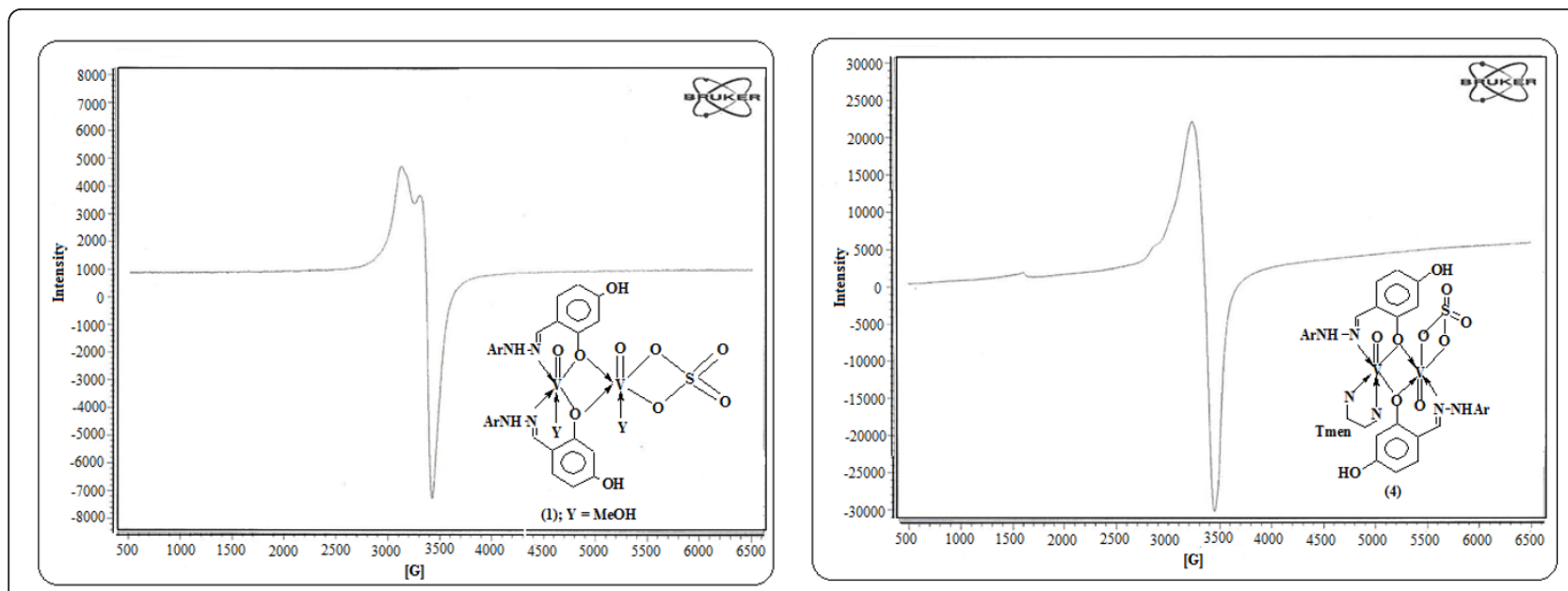

Figure 3 The X- band ESR spectra of powdered samples of complexes 1 and 4 .

$\left[(\mathrm{VO})_{2}(\mathrm{HL})_{2}\right.$ (Tmen) $\left.\mathrm{SO}_{4}\right] .6 \mathrm{H}_{2} \mathrm{O}(4)$ undergoes another structural rearrangement as shown in Scheme 4.

\section{Experimental}

\section{Materials}

The chemicals used in this investigation were of the highest purity available (Merck, BDH, Aldrich and Fluka). They included vanadyl sulfate monohydrate, N, $\mathrm{N}, \mathrm{N}^{\prime}, \mathrm{N}^{\prime}$ - tetramethylethylenediamine (Tmen), 1,10-phenanthroline (Phen) or 8-hydroxyquinoline (Oxine), otoluidine, ethyl acetoacetate, $\mathrm{POCl}_{3}$, sulfuric acid, hydrazine hydrate and 2,4-dihydroxybenzaldehyde. Organic solvents were reagent grade chemicals and were used without further purification.

\section{Physical measurements}

Microanalyses were carried out on a Perkin- Elmer 2400 CHN elemental analyzer. Thermal analyses (TG-DSC) were carried out on a Shimadzu- 50 thermal analyzer in nitrogen atmosphere and a heating rate of $20^{\circ} \mathrm{C} / \mathrm{min}$ using the TA-50 WS1 program. Electronic spectra were recorded on a Jasco V-550 UV/VIS spectrophotometer. IR spectra were recorded on a Bruker Vector 22

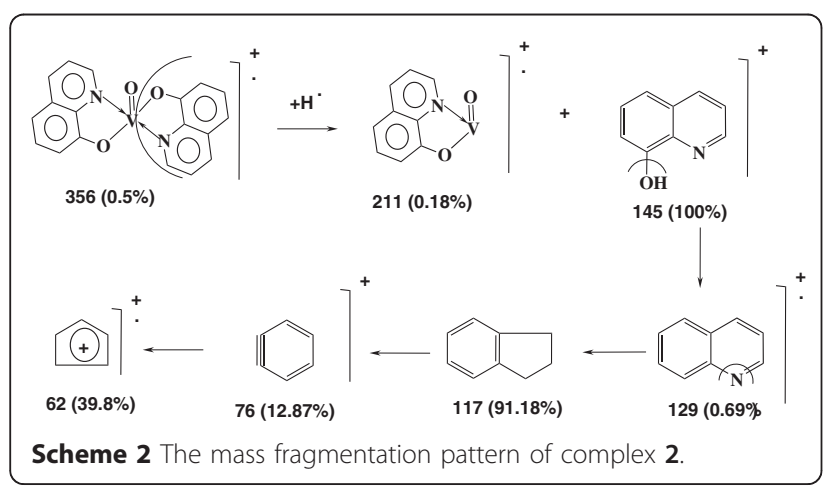

spectrometer using $\mathrm{KBr}$ pellets. ESR spectra were recorded on a Bruker Elexsys, E 500 operated at Xband frequency. Mass spectra were recorded at $70 \mathrm{eV}$ on a gas chromatographic GCMSQP 1000- EX Shimadzu mass spectrometer. Molar conductance was measured as DMF solutions on the Corning conductivity meter NY 14831 model 441. Magnetic susceptibility was measured at room temperature using a Johnson Matthey, MKI magnetic susceptibility balance. Melting points were determined using a Stuart melting point apparatus.

\section{Preparation of the phenolic hydrazone}

An ethanolic mixture of 2-hydrazinyl-4,8-dimethyl quinoline $(0.01 \mathrm{~mol})$ and 2,4-dihydroxybenzaldehyde $(0.012$ $\mathrm{mol}$ ) was refluxed for $1 / 2 \mathrm{~h}$. The formed yellow compound was filtered off, washed with ethanol and crystallized from ethanol as described in our previous publication [5].

\section{Synthesis of the complexes (1-4)}

A methanolic solution of $\mathrm{VOSO}_{4} \cdot \mathrm{H}_{2} \mathrm{O}$ was added gradually to a methanolic solution of the phenolic hydrazone in absence (complex 1) and in presence of Oxine, Phen or Tmen (complexes 2-4) at the mole ratio 1: 1: 1. The reaction mixture was refluxed until the solid complex was precipitated. Then, the isolated complexes were filtered off, washed with methanol, then diethyl ether and

Table 4 Thermodynamic and kinetic parameters ${ }^{a}$ of complex 3.

\begin{tabular}{ccccccc}
\hline Stage & $\mathbf{T}(\mathbf{K})$ & $\mathbf{A} \times \mathbf{1 0 ^ { - 9 }} \mathbf{~ s e c}^{-1}$ & $\mathbf{E}^{*}$ & $\Delta \mathbf{H}^{*}$ & $\Delta \mathbf{G}^{*}$ & $-\boldsymbol{\Delta} \mathbf{S}^{*}$ \\
\hline $1^{\text {st }}$ & 427 & 38.251 & 20.233 & 16.69 & 36.004 & 45.234 \\
$2^{\text {nd }}-$ & 625 & 14.133 & 12.118 & 6.931 & 42.344 & 56.662 \\
\hline${ }^{a} \mathrm{E}^{*}, \Delta \mathrm{H}^{*}$ and $\Delta \mathrm{G}^{*}$ are in $\mathrm{k} \mathrm{J} \mathrm{mol}{ }^{-1}$ while $\Delta \mathrm{S}^{*}$ is in $\mathrm{J} \mathrm{mol}^{-1} \mathrm{~K}^{-1}$ &
\end{tabular}




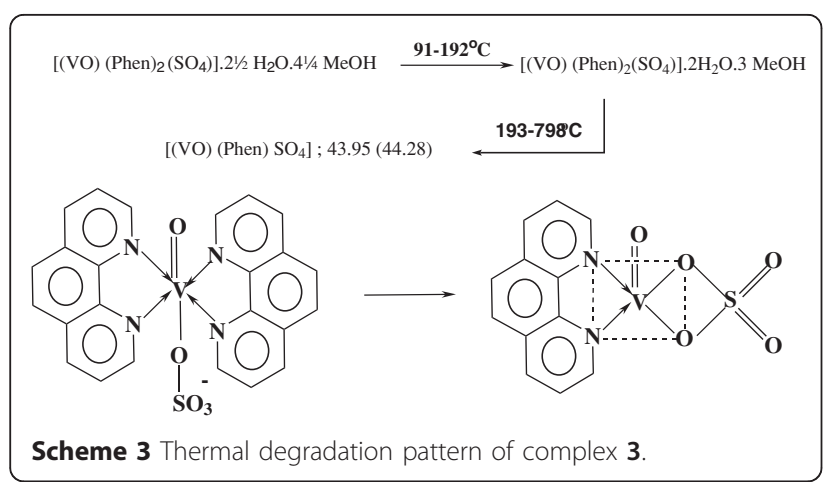

finally dried in vacuo. The obtained complexes (Table 2) are colored and quite stable in atmospheric conditions. The complexes are insoluble in water and most common solvents; but they are soluble in DMF and DMSO solvents.

\section{Conclusion and comments}

Trials to prepare mixed ligand complexes via the reaction of the phenolic hydrazone $\left(\mathrm{H}_{2} \mathrm{~L}\right)$ with $\mathrm{VOSO}_{4} \cdot \mathrm{H}_{2} \mathrm{O}$ in presence of Oxine or Phen were unsuccessful. Instead, an Oxinato complex (2) or a Phen complex (3) were obtained. In contrast, these trials were successful in case of the more flexible aliphatic base (Tmen) where a mixed ligand complex (4) was obtained. The obtained complexes have an octahedral arrangement except complex 2 which has a square pyramid arrangement. Also,

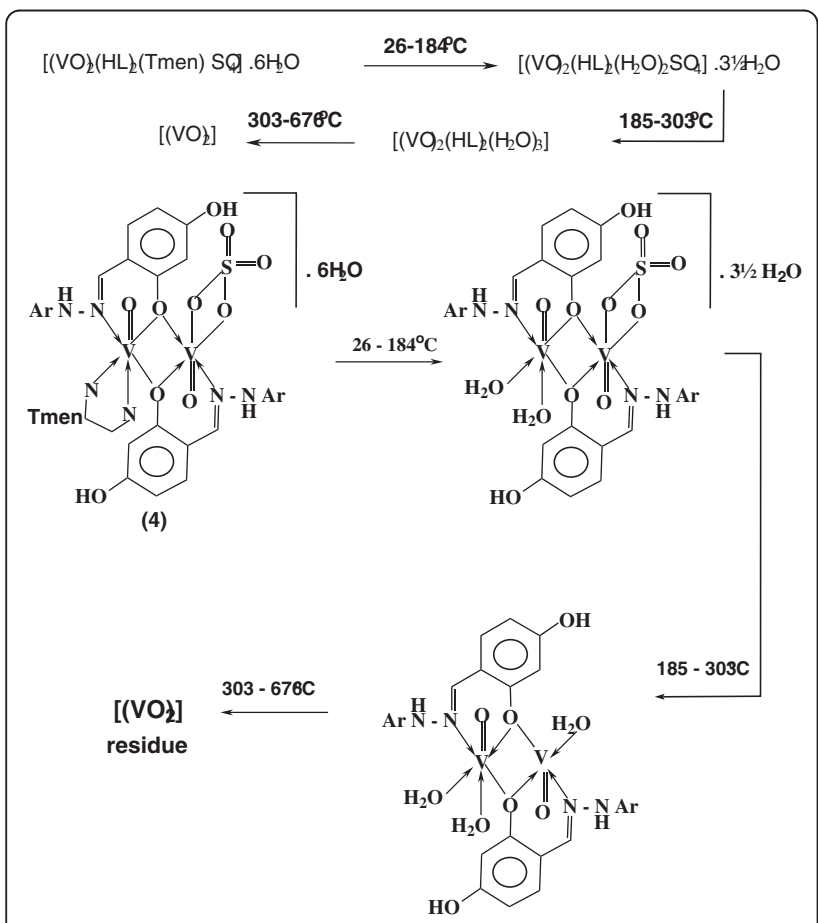

Scheme 4 Thermal degradation pattern of the adduct $\mathbf{4}$. they reflect the competency power towards the oxidovanadium (IV)- ion, and the following order holds; Oxine or Phen >> phenolic hydrazone $\left(\mathrm{H}_{2} \mathrm{~L}\right)>$ Tmen. This order reflects that the nucleophilicity of Oxine or Phen is stronger than that of phenolic hydrazone $\left(\mathrm{H}_{2} \mathrm{~L}\right)$.

\section{Authors' contributions}

HSS designed the study, analyzed the data and drafted the manuscript. MAM prepared the organic ligand and its complexes. Both authors read and approved the final manuscript.

\section{Competing interests}

The authors declare that they have no competing interests.

Received: 5 May 2011 Accepted: 16 August 2011

Published: 16 August 2011

\section{References}

1. Tamasi G, Chiasserini L, Savini L, Sega A, Cini R: Structural study of ribonucleotide reductase inhibitor hydrazones. Synthesis and X-ray diffraction analysis of a copper(II)-benzoylpyridine-2-quinolinyl hydrazone complex. J Inorg Biochem 2005, 99:1347-1359.

2. El-Behery $M$, El-Twigry $H$ : Synthesis, magnetic, spectral, and antimicrobial studies of $\mathrm{Cu}(\mathrm{II}), \mathrm{Ni}(\mathrm{II}) \mathrm{Co}(\mathrm{II}), \mathrm{Fe}(\mathrm{III})$, and $\mathrm{UO}_{2}(\mathrm{II})$ complexes of a new Schiff base hydrazone derived from 7-chloro-4-hydrazinoquinoline. Spectrochimica Acta (A) 2007, 66:28-36.

3. Gupta LK, Bansal U, Chandra S: Spectroscopic and physicochemical studies on copper(II) complexes of isatin-3,2'-quinolyl-hydrazones and their adducts. Spectrochim Acta (A) 2006, 65:463-466.

4. Gupta LK, Bansal U, Chandra S: Spectroscopic and physicochemical studies on nickel(II) complexes of isatin-3,2'-quinolyl-hydrazones and their adducts. Spectrochim Acta (A) 2007, 66:972-975.

5. Seleem HS, El-Inany GA, El-Shetary BA, Mousa M: The ligational behavior of a phenolic quinolyl hydrazone towards copper(II)- ions. Chemistry Central Journal 2011, 5:2.

6. Seleem HS, Mostafa M, Hanafy Fl: Stability of transition metal complexes involving three isomeric quinolyl hydrazones. Spectrochim Acta (A) 2011, 78:1560-1566.

7. Seleem HS: Transition metal complexes of an isatinic quinolyl hydrazone. Chemistry Central Journal 2011, 5:35.

8. Nicolakis VA, Stathopoulos P, Exarchou V, Gallos JK, Kubicki M, Kabanos TA: Unexpected Synthesis of an Unsymmetrical $\mu$-Oxido Divanadium(V) Compound through a Reductive Cleavage of a $\mathrm{N}-\mathrm{O}$ Bond and CleavageHydrolysis of a C-N Bond of an N,N-Disubstituted Bis-(hydroxylamino) Ligand. Inorg Chem 2010, 49:52-61.

9. Crans DC: Chemistry and insulin-like properties of vanadium(IV) and vanadium(V) compounds. J Inorg Biochem 2000, 80:123-131.

10. Crans DC, Yang LQ, Alfano JA, Chi LAH, Jin WZ, Mahroof-Tahir M, Robbins K, Toloue MM, Chan LK, Plante AJ, Grayson RZ, Willsky GR: (4Hydroxypyridine-2,6-dicarboxylato) oxovanadate(V)-a new insulin-like compound: chemistry, effects on myoblast and yeast cell growth and effects on hyperglycemia in rats with STZ-induced diabetes. Coord Chem Rev 2003, 237:13-22.

11. Crans DC, Smee JJ, Gaidamauskas E, Yang LQ: The Chemistry and Biochemistry of Vanadium and the Biological Activities Exerted by Vanadium Compounds. Chem Rev 2004, 104:849-902.

12. Molinuevo MS, Barrio DA, Cortizo AM, Etcheverry SB: Antitumoral properties of two new vanadyl(IV) complexes in osteoblasts in culture: role of apoptosis and oxidative stress. Cancer Chemother Pharmacol 2004, 53:163-172.

13. Molinuevo MS, Cortizo AM, Etcheverry SB: Vanadium(IV) complexes inhibit adhesion, migration and colony formation of UMR106 osteosarcoma cells. Cancer Chemother Pharmacol 2008, 61:767-773.

14. Khassanova L, Collery Ph, Maymard I, Khassanova Z, Etienne JC: Metal Ions in Biology and Medicine. Paris: John Libbey Eurotext; 2002:7:662.

15. Cortizo AM, Molinuevo MS, Barrio DA, Bruzzone L: Osteogenic activity of vanadyl(IV)-ascorbate complex: Evaluation of its mechanism of action. Int J Biochem Cell Biol 2006, 38:1171-1180. 
16. Burgess J: Metal lons in Solution. Great Britain: Wiley; 1981.

17. Hoseini SJ, Nabavizadeh SM, Jamali S, Rashidi M: Ligand substitution

reaction at a binuclear organoplatinum(II) complex. Journal of Organometallic Chemistry 2007, 692:1990-1996.

18. Cusumano M, Giannetto A, Imbalzano A: Kinetics of ligand replacement, in N-substituted ethylenediamine palladium(II) complexes. Polyhedron 1998, 17:125-129.

19. Emara AAA, Abu-Hussein AAA, Taha AA, Mahmoud NH: Spectroscopic, solvent influence and thermal studies of ternary copper(II) complexes of diester and dinitrogen base ligands. Spectrochimica Acta Part (A) 2010, 77:594-604.

20. Ghosh T, Bhattacharya S, Das A, Mukherjee G, Drew M: Synthesis, structure and solution chemistry of mixed-ligand oxidovanadium(IV) and oxidovanadium $(\mathrm{V})$ complexes incorporating tridentate $\mathrm{ONO}$ donor hydrazone ligands. Inorg Chim Acta 2005, 358:989-996.

21. Nakamoto K: Infrared and Raman Spectra of Inorganic and Coordination Compounds. New York: Wiley; 51997.

22. Chatterjee $\mathrm{PB}$, Bhattacharya $\mathrm{K}$, Chaudhury $\mathrm{M}$ : Coordination asymmetry in $\mu$-oxido divanadium complexes: Development of synthetic protocols. Coordination Chemistry Reviews 2011, 255:2150-2164.

23. Ballhausen CJ, Gray HB: Molecular Orbital Theory. New York: Benjamin W.A, Inc; 1965.

24. Mackay KM, Mackay RA: Modern Inorganic Chemistry. Scotland: Thomson Litho Ltd; 31981.

25. Seena EB, M Kurup RP: Spectral and structural studies of mono- and binuclear copper(II) complexes of salicylaldehyde N(4)-substituted thiosemicarbazones. Polyhedron 2007, 26:829-836.

26. Wiger GR, Tomita SS, Rettig MF, Wing RM: Thermal rearrangement, oxypalladation, and molecular structure of "boat-chair" dichloro(3methylcycloocta-1,4-diene)palladium(II). Organometallics 1985, 4:1157-1161.

27. Xie WH, Wang BQ, Xu SS, Zhou XZ, Cheung KK: Synthesis, structure and thermal rearrangement of tetramethyldisilanebridged bis (cyclopentadienyl) diiron complexes with a phosphite or phosphine ligand substitution. Polyhedron 1999, 18:2645-2650.

28. D'ascenzo G, Wendlandt WW: The thermal properties of cobalt(II), nickel (II) and copper(II) iminodiacetates. Thermochimica Acta 1975, 13:333-339.

doi:10.1186/1752-153X-5-47

Cite this article as: Seleem and Mousa: Ligand substitution reactions of a phenolic quinolyl hydrazone; oxidovanadium (IV) complexes. Chemistry Central Journal 2011 5:47.

Publish with ChemistryCentral and every
scientist can read your work free of charge
"Open access provides opportunities to our
colleagues in other parts of the globe, by allowing
anyone to view the content free of charge."
W. Jeffery Hurst, The Hershey Company.
- available free of charge to the entire scientific community
- peer reviewed and published immediately upon acceptance
- cited in PubMed and archived on PubMed Central
- yours - you keep the copyright
Submit your manuscript here:
http://www.chemistrycentral.com/manuscript/

